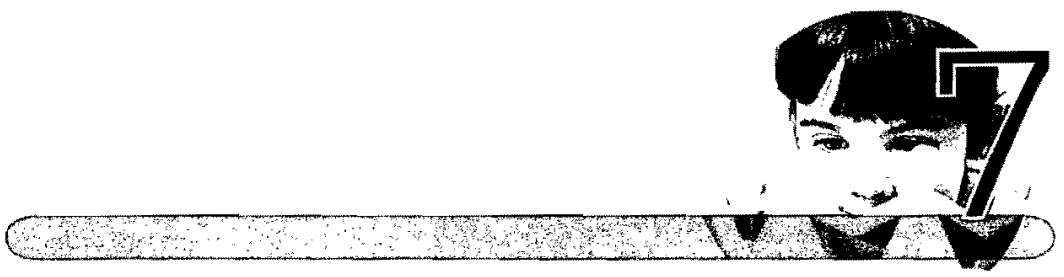

\title{
Including fathers in work with vulnerable families
}

Richard Fletcher

\section{Learning goals}

This chapter will enable you to:

1. Recognise the potential of child and family practitioners in health and education settings to engage fathers (and father figures) of vulnerable children in ways that will enhance their ability to nurture and protect their children

2. Understand how community and staff perceptions, social policy and institutional practices may act as barriers to fathers' participation in child and family settings

3. Become familiar with recent research evidence pointing to fathers' positive influence on children's well-being and consider the implications of this

4. Recognise the complexity of changing service procedures and practice to include fathers fully in a way that enhances family well-being

5. Reflect on the professional and personal challenges that may be faced when attempting to include fathers in services targeting vulnerable children and their families.

\section{Introduction}

Involving fathers in the lives of children is consistent with the goals of nearly all family services. Child and family services routinely declare that they wish 
to form partnerships with parents to ensure the best outcomes for children and most practitioners would consider that having both partners involved in parenting programs is likely to be associated with better outcomes than if services rely on the mother to relay information and ideas to her partner. The reality, however, is that while staff might wish to see fathers involved, when services say parents they usually mean mothers and when evaluators record family involvement in the service it is the mothers' involvement that is assessed. The focus on mothers reflects the history of public support for families with young children through maternity services and mothers' clubs and while the language and naming of services has changed to reflect a broader view of family practice the reality is that participants are overwhelmingly mothers and staff in child and family services are mostly women.

In previous times the focus on mothers might not have presented a problem but community values have shifted to endorse fathers' involvement with young children and the science of infant development has challenged the exclusive focus on mother-infant interaction by demonstrating an independent effect for father-infant and father-child relationships. At the same time, however, increasing awareness of sexual abuse and domestic violence perpetrated by men has added to the complexity of involving fathers in child and family services. In this chapter the context of family service provision to fathers is explored before describing recent research evidence pointing to a new role for fathers in child development. Examples of practice are used to illustrate some of the complexity involved when family-related services begin shifting their practice to include fathers while also remaining committed to mothers' and children's well-being.

\section{Has fathering changed?}

It is now common to notice fathers in shopping malls pushing strollers or walking with children in the park and to see advertisements for everything from computers to life insurance now include images of young, well-toned fathers nursing happy infants or holding happy young children. Community surveys regularly report strong endorsement of the value of fathers taking an equal share of the care of children, and governments in many countries advocate for parents to share home duties and work opportunities equally through gender equality quasi-government commissions, boards and the like. We have new services such as antenatal groups for fathers (Chapter 13 describes the spread of one such program in Australia), fathers' parenting classes and fathers' websites and forums that did not exist for earlier generations. Recent changes to family law in Australia have stressed the right of children to an ongoing relationship with both parents in the absence of violence or abuse, and there is debate about the extent of paternity leave that should be offered to new fathers. The enthusiasm of the media for stories 
featuring fathers means that any changes in fathers' behaviours or new developments in fathers' roles are widely promulgated.

However, while the amount of time that fathers spend with their children seems to be increasing in most Western countries, the role of fathers in all societies remains clearly different from that of mothers. This is particularly the case in the period surrounding childbirth; it is mothers who develop a special relationship with their infant through the pregnancy - a relationship that cannot be duplicated by fathers. Another fermale domain is breastfeeding, which, whether sustained or not, also clearly defines the mother as nurturer and father as 'support person'. The different roles for male and female parents are reflected in work patterns surrounding the birth. Even in countries that have strenuously promoted gender equity policies and encouraged fathers to take leave from their work to care for their children, the primary role of mothers in infant care remains, in no county do fathers take as much time away from their work and careers to care for children as mothers do.

One way to gain some perspective on the changes in the social definition of fatherhood is to examine the content and interpretation of family law as it applies to fathers and fatherhood. Legislation covering the whole gamut of family relations, from inheritance and probate to incest and child custody incorporates definitions of who is a father and what are his rights and obligations. By defining the 'father' through his roles, rights and responsibilities, the law sets in train a discourse that permeates the fine grain of society; legal debate surrounding fatherhood can provide an indication of changes in our social definitions.

\section{Fatherhood in the law}

New legislation has been introduced in many Western industrialised countries that alters the legal basis of paternity and helps to shape fathers' options in rearing their children. Nordic countries have pioneered paid paternity leave for fathers as part of their efforts for more equal gender relations in families (Gíslason, 2007). A second wide-ranging shift has been led by the United Nations in its Convention on the Rights of the Child which emphasises, among basic needs for care and protection, children's right to ongoing personal contact with both parents in the event of separation. Countries who are signatories to the convention (140 have signed) have made changes to their laws regarding children including those dealing with separation and divorce. In 2006, Australia passed the Family Law Amendment (Shared Parental Responsibility) Act 2006 making both parents responsible for decisions about their child through the concept of 'equal shared parental responsibility' (Caruana, 2006, p. 56). A third important change has been the development of artificial conception procedures that have required separating legal fatherhood from biological 
fatherhood. Legislation in some states of Australia for example expressly deems that a sperm donor should not be considered the father of a child conceived through the use of his sperm (Fletcher \& Willoughby, 2002).

However, as historians have noted, new conceptions of social roles that may be incorporated into legislation are not universally adopted; rather than swapping one idea of fatherhood for another, different or even contradictory notions of fathers and fathering may coexist for considerable periods of time.

\section{The task for child and family workers}

Those working in child and family services have to navigate between the competing notions of what society, and what individuals, expect of fathers. Clearly some aspects of fathers' roles have changed but many have not. The evidence that most men and women in the community (including most service providers) want fathers to be involved and yet few fathers are engaged with child and family services suggests that involving fathers must be a complex task, one that cannot be accomplished by simply inviting fathers to participate alongside mothers. When staff of an organisation make the decision to include fathers, it is important to appreciate the scope of the task and the considerable changes that may be involved.

Practitioners who have attempted to recruit fathers on the basis that everyone agrees with father involvement and therefore all that is required is an invitation, have often been disappointed in fathers' responses. In many cases these practitioners have put in extra time and effort to hold the event after hours and often to prepare the food, displays and activities. When only a few fathers turn up, the staff are then tempted to conclude that there is no interest from the men and to withdraw from the task of including fathers saying 'Get fathers in? Yes we tried that...it didn't work.' Two important, initial steps to include fathers are a) identify the barriers that currently exist to prevent services addressing the needs of fathers and b) develop an evidencebased rationale for why fathers should be involved in the first place.

The internal, systemic and organisational barriers to including fathers are described in the following sections along with implications for service providers. Recent research on father-infant and father-child relationships is then outlined to provide an evidence base for including fathers.

\section{Barriers for fathers: internal constraints}

Qualitative studies using convenience samples in the US and the UK have documented men's feelings of frustration, helplessness, anxiety, discomfort 
and nervousness in the context of antenatal classes and their resentment at feelings of being ignored at the birth (Chapman, 2000; Henderson \& Brouse, 1991; Jordan, 1990; Nichols, 1993; Smith, 1999). Australian research has also shown that new fathers are often unprepared for the relationship changes occasioned by the birth, and that they are unaware of services available after the birth that are able to assist families (Fletcher, Silberberg \& Galloway, 2004). Yet, when expectant fathers are surveyed about hospital services they are generally very positive and when a large representative sample $(n=1000)$ of Australian fathers was asked to identify their needs the most common responses were 'don't know' (16\%) and 'nothing needed' (14\%), with only $3 \%$ identifying a need for more assistance from services (Russell et al., 1999).

Rather than conceptualising help seeking as an individual, singular decision, researchers in the mental health area describe 'help-seeking pathways' involving multiple social interactions to identify and assess the psychosocial need and multiple decision points leading to engagement with services and treatment (Aoun, Palmer \& Newby, 1998). Services may underestimate the lack of informal knowledge among farhers of how family support services operate. Fathers may not seek help because they (correctly) believe that their infant's crying or their child's unsettled behaviour will probably subside over time. They may also expect that their own distress will be temporary. Fathers' lack of experience in managing family relationships with new children may also make the recognition of child development or relationship problems by fathers less likely. Fathers' perception of the risk of embarrassment might be another factor, deterring them from seeking help from services or preventing the discussion of help for parenting problems within their social networks.

\section{Barriers for fathers: opportunity constraints}

In contrast to mothers, who of necessity attend antenatal and post-natal services, fathers' attendance is optional. Fathers do not need to have health professionals assess their weight, blood pressure and so on, and so do not need to attend clinics for procedures or consultations. Work patterns and social values also mean that it will probably be the mother who contacts the health or welfare services for support with any problems to do with the children. As a result, a major obstacle to engagement with fathers is the lack of regular contact with health and welfare services.

Although there are no published statistics of fathers' attendance at perinatal health visits, men are less likely than women to visit general practitioners during the primary parenting years and are less likely to contact telephone parenting services for information and support. In the welfare area the reluctance of practitioners to contact biological or stepfathers in cases where a child is considered 'at risk' is well documented (Scourfield, 2006). 
Fathers also face considerable time pressure. Fathers in Russell et al.'s (1999) survey most frequently cited lack of time and the competing demands of work as a barrier to becoming involved with their children. However, the lack of time is, to some extent, a subjective judgement influenced by the father's perception of the importance of the activity concerned. For example, the prediction of a father's involvement with children from the father's workplace demands - such as the number of hours worked - is relatively weak; the amount of involvement is not simply a result of his lack of availability. The experience of father-involvement programs is that once the fathers see the point of the activity then ways to manage work demands are often found (Fletcher, 2004).

\section{Barriers for fathers: service constraints}

From the time that a pregnancy is confirmed, the mother becomes the client of the health service and her pregnancy becomes the focus of visits with her general practitioner or to the antenatal clinic. Hospital data collections may not record the father's name, and the materials given to mothers during her hospital stay may not even mention fathers, referring instead to mothers and their 'support person'. Analysis of popular commercial childrearing information in North America found that fathers were rarely mentioned, and when they were their role was depicted as predominantly ancillary to mothers and voluntary (Fleming \& Tobin, 2005). A recently completed review of parents' information needs in Australia found that perinatal parenting information is usually directed explicitly to mothers and that there is widespread recognition among service providers that the father's role is considered an 'add on' and insufficiently addressed (Centre for Community Child Health, 2004).

Evidence from a wide range of studies also suggests that the attributes of staff and the design of services may unintentionally inhibit a father's participation. A review of fathers' access to family services identified 13 barriers to fathers' participation (Fletcher, Silberberg \& Baxter, 2001). Professionals' attitudes to fathers, their lack of skills to engage with men, and the lack of appropriate models of male service delivery, were identified as hindering fathers' involvement. A paucity of appropriate information and resource materials targeting fathers and service providers' lack of knowledge about men were also noted (Fletcher, Silberberg \& Baxter, 2001). The lack of knowledge about men may derive, in part, from the gendered nature of the workforce in health and family services. Although there is no evidence that male clinicians provide better care to males, the need for family services to reflect the diversity of the clients being serviced is gaining recognition. In Western industrialised countries fathers are unlikely to encounter males in any of the front-line areas of midwifery, paediatric nursing, or among nurses making 
home visits in the weeks after the birth. Social workers, family workers and welfare workers also tend to be female.

\section{Interaction of barriers}

The way that these factors might interact to marginalise fathers was recently described as part of an invited contribution to a special issue of The Medical Journal of Australia' on men's health:

When Michelle and Anthony attend Michelle's GP after the positive pregnancy test, Anthony expresses his support but asks few questions. When asked about the couple's intentions for pregnancy care Anthony's quick glance toward Michelle flags his uncertainty. For the next visits Michelle attends the clinic alone. Anthony does participate in the ultrasound consultation and he joins in when asked during the antenatal classes but he accepts that the emphasis throughout is appropriately on the mother and a successful birth. During the birth he wonders if he is in the way and is grateful in the end to have a healthy mother and baby. Post-birth, when the home-visiting nurse arrives, Anthony goes to make coffee and misses most of the discussion. His return to work precludes him attending the check-ups for mother and baby at the doctors.

Anthony's minimal role with health professionals is mirrored at home and in social settings. Michelle reads the books, brochures and magazines and tells Anthony about popular names, baby development, and the dangers of SIDS [Sudden Infant Death Syndrome]. Anthony is affectionately ribbed by workmates about sleep deprivation and nappy changing and although one of his mates has just become a father Anthony has little chance to learn about the business of fathering. Social time with the new baby is dominated by eager mothers or girlfiends and there are few opportunities for Anthony to try out 'holding a new baby' without drawing attention to himself.

(Fletcher, Matthey \& Mariey, 2006)

Some of the limitations of programs for families of young children in engaging fathers have been discussed in Chapter 6 . Developing new father-inclusive models of service will require addressing all of the above barriers: fathers' lack of experience with infants and children's care and poor understanding of services; the lack of contact between family-based services and fathers; and the paucity of father-inclusive models of service delivery.

\section{Implications for services}

There is an important lesson here for any family service that is attempting to attract men to activities or programs at a centre - check the walls to see what message they are sending to the families. Health and welfare centres, for 
example, frequently have posters about domestic violence or sexual assault, important issues that need to be raised. But for many services these are the only messages directly talking to men. Young Indigenous fathers told us, when we interviewed them about their experience of community services surrounding the birth, that all the posters in the waiting rooms were about domestic violence, sexual abuse, stalking women or drug and alcohol abuse. As one father put it 'All they think about when they see a father is the bad things he done' (Hammond et al., 2004).

Changing the messages from the walls is relatively simple. Over recent years a variety of posters promoting involved, positive fatherhood for services have been developed, including posters for specific groups such as Indigenous fathers and many are available at low cost (see the useful websites at the end of this chapter). Of course, posters are not the only channel for the environment to give a message to fathers. Some child and family centres have taken the next step of examining the colour schemes and general décor in the centre for how it might appear to a father. Most centres strive for a soft pastel look that reflects the 'normal' environment for mothers and children; the colours that might make the space more male friendly can be seen in advertising for products that are aimed at male customers - they are often bolder and include greater contrasts.

In other places centres have created a 'dads' corner' where photographs of fathers using the centre and notices directed explicitly to fathers can be displayed. Using photographs of 'real' fathers has the added bonus of underlining the normality of fathers' involvement. Posters or images of sports stars or celebrity fathers have their uses but locally produced images of 'ordinary' fathers can send the important message that 'fathers who are just like you' get involved at this service.

Some services have used notices to make their processes, which mothers already know, clearer to fathers. For example, when a father, who doesn't usually pick up his child, arrives at the early childhood centre he may not know whether he is supposed to take home all the material alongside his daughter's bag or leave it, he may not know where the sign-out book is or that he should fill out the form for photographs or tomorrow's excursion to the park and leave it in the box near the director's office door. Having clearly set out instructions (information that mothers who attend often will already know) can reduce the father's sense that he is out of place.

An extension of this idea is to examine how fathers gain knowledge of a service before they walk in the door or attend an event such as a parenting course or clinical appointment. What pamphlets, advertisements or publicity might they have seen that explains who the service is for? How does the induction or referral process suggest who is expected to attend? What comments might their family or friends have made about the style of the service that will help form their attitude to the service? 
An important point to grasp in answering these questions is that although services intend to include everyone when using the words 'parent' or 'family', that is not how these words are understood in the community. It would be usual, for example, for any letter arriving at the home addressed as 'Dear Parent' to be handed to the mother, who is the one most likely to be dealing with family matters. Services wanting to communicate with the fathers in the families have sometimes added 'Dad this means you' after '"Dear Parent' or added a 'Message for Dads' with a separate section highlighting information for fathers.

For many services the first contact with a father might be by phone and the following scenario is one that I have used in many training workshops for early intervention staff wishing to hone their skills to effectively reach fathers:

\section{Scenario}

Kerry works at XYZ Early Childhood Service. Jennifer Farmer has been in contact with her seeking a place on Monday, Tuesday and Wednesday for her two year old daughter Jasmine. Kerry is calling to inform the family that these days are now available and to ask if a place is still required. As it happens Mr Farmer answers the phone. The following conversation takes place:

Father: Hello?

Kerry: Hello - is that the Farmer residence? I am calling about a place for Jasmine..

Father: Who is this?

Kerry: Hi. This is Kerry from XYZ Early Childhood Service. I am calling about a place for Jasmine.

Father: Ummm...

Kerry: Mrs Farmer put Jasmine's name down for Monday to Wednesday....

Father: Oh... OK...

Kerry: And we'd like to know if you still want the three days for Jasmine...

Father: OK. Hold on and I'll get Jenny for you...

Many child and family practitioners find this scenario very familiar. It is often mothers who search out which services are available and then negotiate the best arrangements for the family. The telephone contact with the father in this example presents an opportunity to convey to the father that he is also seen as important by the service.

In the father-inclusive practice training workshops the participants role play various ways of engaging the father in this brief window of contact. The task for Kerry in this scenario is to convey that, for this service, the involvement of the father is seen as important. Strategies suggested during the workshops include asking him about the things that Jasmine likes to do, asking if he knows where the XYZ Early Childhood Service is located or 
discussing who will be dropping Jasmine off or picking her up. In the role plays participants often falter when the role-playing father asks why the service wants to involve him because his partner Jenny has always handled these things in the past. In spite of the enthusiasm for fathers' involvement with children's care few services have developed any detailed rationale for including fathers and staff are frequently at a loss if they are required to articulate the thinking behind efforts to reach them.

\section{Activities}

Consider how you would explain the importance of including fathers to colleagues who are concerned about their ability to work with fathers; a manager who requests evidence for allocating resources to work with fathers; a father who is unsure about whether to undertake a 'fathering' activity; and a single mother.

Visit a child and family service. Try to see the physical layout as a new, relatively inexperienced father might. What messages about the service would stand out? What, if anything, would tell the father that the service is actively seeking his involvement?

\section{Evidence of fathers' impact}

The task of involving a father in a home visit, a parenting group or even in a conversation about the best course of action for his child may be made difficult because it takes place against a backdrop of previous experiences like those of Michelle and Anthony described above. If things are to change it will require considerable effort and thought by practitioners wishing to refashion services to include fathers alongside mothers in supporting their children.

The question which follows is: 'Why should this service invest precious resources in implementing changes to include fathers?' Developing new procedures has cost implications as including fathers implies taking on additional clients or additional tasks to support families. The evidence of fathers' impact on children's development is crucial therefore in two ways. Firstly if services are to allocate resources to refashioning procedures, skilling staff to engage fathers and reach out to fathers then the evidence that this will improve family well-being is essential.

Equally important will be the practitioners' understanding of the differences between mothers' and fathers' roles. Shifting the basis of the work from 'mother as central and father as helper' to an approach that includes father-infant and father-child relationships will mean grappling with how fathers' interactions influence both the child and the mother-child relationship. The recent developments in our understanding of how fathers' 
positive interactions can foster children's development will be important knowledge for managers, service planners and practitioners alike.

Studies assessing fathers' impact on development have followed families over several years measuring fathers' interaction at an early age and then children's well-being some years later. In a study by the National Institute of Child Health and Human Development in the US, which examined parental factors that predicted school readiness, children who had fewer behaviour problems and higher social skills came from families where the fathers were sensitive and supportive of autonomy. An emotionally intimate marital relationship also added to the positive effect of these factors (NICHD Early Child Care Research Network, 2004).

A more recent study, also from the US, compared the influence of fathers and mothers from a low income sample on their children's cognitive development. Children with two supportive parents scored highest on measures of maths and language while those whose parents were both unsupportive scored lowest. What was also clear, however, was that the positive effect of having one parent supportive did not depend on whether that parent was a mother or a father. Elevated cognitive abilities were just as likely to be apparent amongst children with a supportive father as those with a supportive mother (Martin, Ryan \& Brooks-Gunn, 2007).

Fathers' effects on well-being do not stop at childhood. As part of the US National Longitudinal Study of Adolescent Health a nationally representative sample of adolescents was tested from Grade 7-12 to measure their relationship with their fathers and mothers and their level of depression. Over the five years of the study the quality of the father-adolescent relationship, as judged by the adolescent, was found to be equally predictive of the adolescents' mental health as the mother-adolescent relationship (Videon, 2005).

Studies such as these provide a powerful argument for recognising a role for fathers separate from that of mothers, and for challenging the notion of father as 'helper' to the mother. It has long been assumed, for example, that the mother-infant bond was the template for the father-infant bond, and that while the relationship with the mother was fundamental to children's well-being the relationship with the father was an optional extra. For their part, fathers assumed that they had no role to play with young children until they could be physically active or could ' $k$ ick a footy'.

Recent research has challenged the assumptions of practitioners and fathers alike. Infants' secure or insecure attachment, for example, is now thought to be largely independent for mothers and fathers. When the results of several studies assessing the attachment of infants were analysed, it was recognised that while many infants did have a secure attachment to both their mother and their father, they could be securely attached to the mother but insecurely attached to the father or the reverse. Contrary to the 'helper' 
notion of fathers, an infant may form a secure attachment to the father alongside an insecure attachment to the mother (van Ijzendoorn \& De Wolff, 1997). What is more, when a new farher is depressed (and therefore less responsive and affectionate) the effect on the well-being of the infant is similar to when the mother is depressed.

Since the early 1980 s we have known that depressed mothers' early parenting, specifically their insensitivity to infant cues and inability to provide effective emotional regulation, is associated with the development of insecure or disorganised infant-mother attachment and subsequent reduced social competence and increased behaviour disorders (Ashman \& Dawson, 2002). What has recently been established is that fachers' depression is also an important factor in children's development. When over 8000 fathers were tested for depression eight weeks after the birth and their children's behaviour assessed at three and a half years of age, those children whose fathers recorded depressive symptoms in the clinical range two months after the birth were found to have double the risk of behavioural and emotional problems (Ramchandani et al., 2005). The effects of the father's depression was independent of whether the mother was depressed and independent of the father's later mental health suggesting that having a depressed father in the early months of life can have a long-lasting negative effect on children's emotional and social development.

In summary recent research shows that:

Father involvement can have a significant and important effect on the well-being of children

Fathers influence their children's development directly rather that solely as a 'helper' to the mother

Infants respond to fathers as well as mothers and benefit from their relationships with fathers independently of their relationships with their mothers

Infants/children do best when they have a secure relationship with both mother and father and when the relationship between mother and father is warm and affectionate.

\section{What about 'bad' dads?}

The evidence for early intervention with mothers is now strong enough for governments of all persuasions to endorse programs and policies that aim to support vulnerable families with young children. However, although the evidence for fathers' impact on children's development is also now well-founded, and in many areas policies and programs are moving to include a focus on fathers within early interventions for vulnerable families, the provision of support for fathers remains problematic. One reason for the faltering progress of father 
inclusion is described above - societies and individuals continue to hold contradictory notions of fatherhood and practitioners frequently underestimate the changes required to incorporate fathers fully into mainstream services. As well, the research on a father's role in child development is relatively new, so that training and theoretical support for father inclusion is still emerging.

However there is also the important issue of violence and abuse to incorporate into any changes seeking greater father involvement. Particularly in vulnerable families, practitioners may be well aware that part of the diffculty facing the family is violent behaviour from the father. In this situation it will be important to avoid any simplistic approach that ignores difficult issues of violence or abusive behaviour, thereby ignoring the needs of the mother. Equally futile however, is the approach that ignores the father and his relationship with the children because the father is (or once was or might be) violent. In a recent example from my own work, a parenting skills program refused to provide educational sessions for parents in a housing estate program because there may be men attending the course. "They'll be wife bashers' was the only explanation offered for the refusal.

As part of the reconceptualising of fathers' roles, researchers have questioned the exclusive emphasis on providing safety and comfort for young children and have turned their attention to how parents can foster children's confidence and exploration. Fathers' 'rough and tumble' play has been identified, not only as common among fathers and children in many cultures, but as beneficial for child development (Paquette, 2004). There has also been the suggestion that fathers' interactions with young infants are typically less modulated than mothers' with more unexpected peaks of excitement, again with positive developmental implications (Feldman, 2003).

However, for those working with vulnerable populations, the notion of encouraging fathers' energetic play with children may seem too risky. Indeed, there is evidence to support practitioners' caution with simply encouraging more involvement (of any type) from fathers. A study of over 1100 fathers and their five year old children found that for children whose fathers had high levels of antisocial behaviour, the more time they lived with their father, the more behaviour problems they exhibited (Jaffee et al., 2003). In this study the problematic fathers were defined as having high levels of antisocial activity warranting a diagnosis of antisocial personality disorder and so would form a rather small group within the population of fathers. A potentially larger group among those coming into contact with child and family services are fathers who might be involved in domestic or family violence. However, practitioners in child and family services may feel ill-equipped to address the complexity of issues in a situation of family violence or even of family anger. As a UK volunteer expressed during a training session for home visitors: 
would get back in the car and I would ring the office. It's not our place to go into somewhere where a) we don't know the situation and b) we could be putting ourselves in danger..

The risk of confronting antisocial or angry behaviour should be taken seriously when providing family-based services. The possibility of encountering an angry or even violent parent requires care in the overall design of the service, in training and support for staff, and in establishing safety protocols and procedures. However the risk that there may be domestic violence should not preclude the family having contact with services, nor should it prevent the service including strategies for engaging with the father around his role in the family. Addressing violence and conflict as part of a comprehensive response to family difficulty can enhance services' effectiveness with families facing serious disruption and stress. For example, this is how the manager of an all-female early intervention service for families with multiple problems (substance abuse, criminal history, parental history of abuse and neglect) described the effects of adopting a focus on fathers:

There was a lot of domestic violence and the emphasis on fathers actually led to us developing a much better policy around domestic violence ... We'd talk to the whole family about it not being safe in the family and that we weren't willing to send a worker into the family until things were safer, but we would still see them in a café or at our rooms. We didn't drop them and we made it clear that we really wanted the man to work on his own stuff ... We also asked two male therapists to talk to us about our own issues - about how we the staff) didn't talk about our own fathers, and how the women staff members felt quite confronted by working with fathers.

(Edwards, 2004, p.9)

\section{Strengths-based practice with fathers}

The notion of 'strengths-based practice' has been coined to describe ways of interacting with families that do not ignore any risk of harm to children, or the need at times for outside agency involvement, but which assume that family members have the capacity to develop supportive and healthy relationships that will enable their children to flourish. Applying this approach to fathers in vulnerable families implies a shift in emphasis from seeing the father as simply a problem - the irresponsible or drug abusing father who is a major cause of the child's vulnerability - to picturing a father with his own vulnerabilities and needs as well as someone whose behaviours may be damaging to family well-being.

As described in the section 'Barriers for fathers' above, a number of factors might make it unlikely that fathers would be involved in initial assessments 
or discussions. However practitioners' training, experience and skills can also influence how inclusive services are of fathers. In the following account an experienced family worker describes how she encourages the father's involvement once it has been established (through telephone contact with the mother) that there is no current violence between the couple.

When I first visit a family I would see the person who made the referral, generally the woman, we'll call her Betty. The first visit would probably happen within business hours, during the day when the kids were at school and Betty's husband (or partner) was at work. The husband generally knew that I was coming. For example, I generally asked, 'Does your husband know that I am coming today?' If Betty responded 'Yes', I then might have said, 'What does he think about you asking for an agency's support around this?' Betty might have said something like, 'Oh he's okay, he doesn't really like talking about these sorts of things but he doesn't mind if I do.'

From here, I would talk with the woman about how she thought I might be able to support them and generally the woman would have some ideas about that. For example, I might have asked Betty what her husband thought, and for her husband's name. Let's say, for example, Betty's husband is John. What I tended to do then was to include John's name in the conversation a lot. I would say something like, If John was here now, what would he be telling me about what's happening between you two?' Betty would then say something like. 'Well, he thinks it's probably my fault because I get depressed and I get down and I get fairly dependent and I can't cope. 'And we would continue to talk.

Those first visits were often short because I established that the work went a lot better if the man was present. For example, I would ask the woman when her husband would be willing to participate, and the woman would generally say that she had to ask him. My intention at this point would be to convey to the woman that I was interested in her husband's opinion as well, that I was interested to see both of them together, and, that I wanted both of them to be comfortable with me. I would make a time for the next visit, which may have been after hours.

(Cantwell, 2004, pp. 94-5)

The ongoing work with vulnerable fathers as part of the support for families will, of course, require more than one conversation and may take a variety of forms depending on the service type and target. There is now recognition, for example, that modifying services to include fathers or father figures of families where children have disabilities may enhance the well-being of all family members. Two examples of ongoing work with fathers, one through home visits and one through centre-based group work are described below. In the first, a pilot attachment-based program for fathers, ultilising videotaping of father-infant interaction is described. In the second, a group program for men addressing anger and violence offers insights into how facilitated discussion can shift fathers' ways of handling family tensions and conflicts. 


\section{A pilot home visiting service for fathers whose partners have post-natal depression}

The service was advertised as 'a free service for new fathers' who may have 'a wife or partner who is not doing so well'. No specific therapy or subsequent action was promised, however, a home visiting model (with a male visitor) was offered at the first interview if appropriate. The practice framework for the intervention, which was developed with mothers, uses videotape to tecord the parent doing 'whatever they enjoyed' with their infant and then viewing the tape together to discuss questions such as 'What is the baby thinking here?'. Father-specific aspects of the intervention were guided by the emerging research on fathers' roles in infant development: fathers' attachment styles with their infant are likely to develop independently to those of mothers; fathers' use of play interactions will be particularly important; and, negotiating a place in the father-mother-infant triangle is a key task for fathers.

A father contacted the service three months after the birth of his child requesting help to be a 'better father'. Although his partner had suffered severe post-natal depression she was not requesting or receiving any professional support at the commencement of the home visits. During the 10 home visits the father's interactions with his infant were videotaped and reviewed in an attachment-based framework. At the conclusion of the home visits the mother and father were interviewed about their experience of the program. The father concluded:

being a good parent is something that you can train yourself to do ... anybody can change a nappy, anybody can pick him up if he is crying ... but what I am looking for out of this is the interaction that you are missing... and that's what I am picking up. Through the DVDs and the video I am picking up those little signals that William wants to interact. Which I think in the long run will bring William and I a lot closer and improve our relationship and that's the whole point of the exercise.

(Fletcher, 2009 p. 99)

In this case, the positive outcome for the father also had a 'knock on' effect for the mother's relationship with their infant. The mother reported:

I think that you [indicating the father] taught me to be more aware. I think that I spent the first months going 'Oh there is this to do and that to do and everything to do' and because [the male home visitor] would ask you 'What do you think he's doing there?' then you would ask me 'What do you think that he is doing there?' and it actually made me more aware that he is actually thinking about things...not this lump that just... I think that made me love him even more because I stopped thinking about all the things that had to be done. 


\section{A group program for men to end violent and abusive behaviour}

Stuart Anderson coordinates the Men's Resource Centre in Northern New South Wales. Using transcripts from men's groups (recorded and transcribed with their permission) he describes the potential for group processes that engage men on the challenges of parenting. Names have been changed to ensure anonymity.

The course offered for men focuses on ending violent and abusive behaviour. An alternative way to describe this focus is that the course assists men to increase safety, trust, respect, care and love within their family. Parenting issues and skills are addressed in the program not because it has dedicated parenting segments but because the desire to be a better dad comes up in nearly every group session. It's like a steady undercurrent that each man is struggling with in some way. One man telling a story about his children fires up all present to think about the dilemmas and frustrations involved in parenting. Even the men who don't have children are stimulated to participate as they recall traumas in their own childhood. It's very rare to hear any of the men talk about a violence-free childhood.

Here is an example of how the group process can assist fathers to rethink their approach to fathering.

Geoff begins with his concern about his wife yelling at their children:

Geoff: Case in point, two girls in the back of the car coming home the other night, yabba yabba yabba. Told half a dozen times by their mother to keep quiet. They're starting to tick me off. I've been driving for four hours. I just put my foot on the brake two kilometres from home, stopped the car. 'Would you girls like to get out and walk now?' 'What for Dad?' 'Because you just won't shut up. 'We'll be quiet Dad. 'Off we went, peace and quiet. I don't want to yell at the girls, I don't want to have a confrontation. It is a conscious choice, I don't want to do this. I just came around the problem in a different way. Their mother was already tense and tired, she was up the anger scale.

Others in the group acknowledged that Geoff made a significant shift from how he used to yell and berate his kids. That he kept his voice calm was seen as great. The facilitators were keeping an eye on this, would others in the group speak up or would they intervene with some further questions? As it happened this group had several men who had attended for a few months and they found it easy to challenge each other. Gary thought that Geoff could do better.

Gary: Do you think you were threatening your kids?

Geoff agreed there was an element of threat in it, but said his voice was calm and he was not angry at the kids himself. He talked about his fear that his wife would abuse the kids because he could see her rising anger. In the following discussion several ways for Geoff to get the message across to his kids were explored. 
Fred who has a back injury and, therefore, is the house husband said that he was in a similar situation the other day. He told the group that at that time he said, 'You are making your mother very angry, is that what you want to do?'

This response was thought by group members to have that same old language that seems to indicate that the kids are responsible for mum's anger. They asked Fred what he would say if he was taking responsibility for his own feelings. Fred struggled with this shift of focus. His habit was to blurt out his ideas on what and who was wrong. It took several attempts before he could name his feelings of anxiety and fear. In that session he only partially succeeded in putting together a sentence that satisfied the other group members. Another man, Nick decided that telling his own story might help Fred.

Nick is a creative steel and metal worker who speaks quietly and firmly. It would be easy to assume that he had never had a problem with anger or abusive behaviour. He related how much of a relief it was not to buy into other people's stress. He used to yell at his wife and daughter to try and stop them arguing.

Nick: It's just easier to stay out of the fights. I'm here if they've finished the fighting and come and talk sense, I'm here for that. I'm not here to get dragged into their fights. My wife said to me, 'It was so great that when we were having that fight you didn't get involved.' It really sunk into her that while she and my daughter were having that fight I was sitting over the other side of the room calmly having a coffee. My quietness allowed her to see what she was doing. She came over and said: "Thank you. I appreciate that you stayed out of it and looked after yourself, that allowed me to have some insight.'

One person taking care of themselves had an effect on the whole family or household. The discussion continued exploring the benefits of a relaxed, calm, whole-picture view rather than the tunnel vision that develops as anger rises.

Nick. It's funny isn't it? When we start putting pressure on ourselves we start falling apart, then all the rest start falling apart and it multiplies - it makes it worse and worse. What Ive found is a calmer approach has made everything else calmer. Even the kids are looking at me different, which is good.

(Anderson, 2004, pp. 54-5)

\section{Activity}

Kerry is seven years old, and has been displaying very challenging behaviours such as frequent tantrums, fighting with other children, and stealing and swearing at her teachers. She lives with her mother Julie and half siblings who she is made to care for (four year old twins and a two year old). An unsubstantiated report notes that Kerry was left alone in the house to care for her siblings during the day for some hours in the school holidays.

Julie received several periods of respite care when she was unable to cope with Kerry. With the new baby (three months old) Julie requests respite with the same Department of Community Services carers as before as Kerry liked them. Julie did not want another child but is against abortion. After having the 
twins, she was diagnosed with post-natal depression, however, no record is available on any treatment or support offered to her or taken up.

Julie's mother lives two hours away and sometimes helps out but finds Kerry's behaviour distressing. She said she won't come to stay as Kerry gets on her nerves.

Eduardo is the father of Kerry but not Julie's other children. He has been away working interstate for the last four years and retumed home some months ago. He has taken Kerry out occasionally. Eduardo shares a house with his mate and lives close by but the house is too small to have Kerry over to stay. There is conflict between Julie and Eduardo, however Eduardo pays child support when he can and always remembers Kerry's birthdays and Christmas.

Eduardo emigrated 10 years ago but all his family still live in Ecuador. He works regular day shifts at the local petrol station three days a week and is hoping to get work in the Goodyear franchise next door.

Julie is advised by the duty child protection case worker that there are no respite carers available. After discussions with Julie, the case worker contacts Eduardo and asks if he would be willing to regularly read to Kerry at bedtime to help her settle into a routine. Eduardo agrees and for the first week arrives at the arranged time to read Kerry a bedtime story. After one week he misses a night, then reads again for three nights then misses a night, then reads for two and misses a night, reads for one night and then stops coming. Julie rings the caseworker and explains that ' $\mathrm{He}$ is too unreliable.'

What is your first guess at why Eduardo stopped the reading sessions? What factors or experiences might push Eduardo away from staying connected with his child? Who or what might encourage Eduardo to stay connected with Kerry?

\section{Conclusion}

While the damaging effects of children experiencing or witnessing abusive behaviour deserve continued recognition, the potential of fathers to promote positive development in children justifies concerted action to expand services' ability to include fathers. Maximising support for vulnerable children will require shifting the policies, procedures and practices in child and family services to be inclusive of fathers.

\section{Useful websites}

About the Fathers Program, Family Action Centre, University of Newcastle provides training, resources and research on father-inclusive practice: www.newcastle.edu.au/research-centre/fac/programs/fathers

The Canadian Father Involvement Initiative develops policy and resources for father-inclusive practice: www.cfii.ca/fion

European Fatherhood presents research and policy on improving gender equality for fathers: www.european-fatherhood.com 
Fatherhood Institute (UK) provides policy and practice materials for fatherinclusive practice: www.fatherhoodinstitute.org/

Head Start is a national program in the USA that promotes school readiness: www.acf.hhs.gov/programs/ohs/index.html

Institute of Family Practice provides training courses relevant to men and family relationships: www.ifp.nsw.edu.au

Men and Family Relationships Services work alongside men to assist them to manage a range of relationship issues with partners, ex-partners and children: www.fahcsia.gov.au/sa/families/progserv/FRSP/Pages/mfr-men family_relationships.aspx

Mens Line Australia provides 24 hour family relationships counselling: www. menslineaus.org.au

Sure Start is a UK Government programme aiming to deliver the best start in life for every child: www.dcsf.gov.uk/everychildmatters/earlyyears/ surestart/whatsurestartdoes/ 
Anderson, S. (2004). Men's anti-violence programs also improve parenting. In R. Fletcher (ed.), Bringing Fathers In: How to Engage with Men for the Benefit of Everyone in the Family. University of Newcastle, Newcastle, NSW.

Aoun, S., Palmer, M. \& Newby, R. (1998). Gender issues in psychosocial morbidity in general practice. Australian Joumal of Social Issues, 33 (4), 335-53.

Ashman, S. \& Dawson, G. (2002). Maternal Depression, Infant Psychobiological Development, and Risk for Depression. American Psychological Association, Washington, DC.

Centre for Community Child Health (2004). Parenting Information Project Volume 3. Australian Government, Canberra.

Cantwell, S. (2004). Involving men in a home visit. In Fletcher R (ed.), Bringing Fathers In: How to Engage with Men for the Benefit of Everyone in the Family. University of Newcastle, Newcastle, NSW.

Caruana, C. (2006). Shared parental responsibility and the reshaping of family law. Family Matters, 74, 56-9.

Chapman, L. L. (2000). Expectant fathers and labor epidurals. The American Joumal of Maternal Child Nursing, 25 (3), 133-8.

Edwards, J. (2004). Making the change towards fathers: The example of the Benevolent Society's Early Intervention Program. In R. Fletcher (ed.), Bringing Fathers In: How to Engage with Men for the Benefit of Everyone in the Family. University of Newcastle, Newcastle, NSW.

Evangelou, M., Sylva, K., Edwards, A. \& Smith, T. (2008). Supporting Parents in Promoting Early Learning: The Evaluation of the Early Learning Partnership Project. University of Oxford, Oxford.

Feldman, R (2003). Infant-mother and infant-father synchrony: The coregulation of positive arousal. Infant Mental Health Joumal, 24 (1), 1-23.

Fleming, L. \& Tobin, D. (2005). Popular child-rearing books: Where is daddy? Psychology of Men or Masculinity, 6 (1), 18-24.

Fletcher, R. (2004). Bringing fathers in: How to engage with men for the benefit of everyone in the family. In R. Fletcher (ed.), Bringing Fathers In: How to Engage with Men for the Benefit of Everyone in the Family. University of Newcastle, Newcastle, NSW.

Fletcher, R. (2009). Brief report: Promoting infant well being in the context of maternal depression by supporting the father. Infant Mental Health Journal, 30 (1), 95-102. 
Fletcher, R., Matthey, S. \& Marley, C. (2006). Addressing depression and anxiety among new fathers. Medical Journal of Australia, 185, 461-3.

Fletcher, R, Silberberg, S. \& Baxter, R. (2001). Fathers' Access to Family-Related Services. University of Newcastle, Newcastle, NSW.

Fletcher, R., Silberberg, S. \& Galloway, D. (2004). New fathers' post-birth views of antenatal classes: Satisfaction, benefits, and knowledge of family services. The Joumal of Peri-natal Education, 13 (3), 18-26.

Fletcher, R. \& Willoughby, P. (2002). Fatherhood: Legal, Biological and Social Definitions: Family Action Centre, University of Newcastle, Newcastle, NSW.

Gislason, I. (2007). Parental Leave in Iceland. Bringing the Fathers in: Developments in the Wake of New Legislation in 2000. Ministry of Social Affairs and Centre for Gender Equality, Akureyri, Iceland.

Hammond, C., Lester, J., Fletcher, R. \& Pascoe, S. (2004). Young Aboriginal fathers: The findings and impact of a research project undertaken in the Hunter Valley. Aboriginal Slander and Health Worker Journal, 28 (5), 5-8.

Henderson, A. \& Brouse, A. (1991). The experiences of new fathers in the first 3 weeks of life. Joumal of Advanced Nursing, 16 (3), 293-8.

Jaffee, S., Moffitt, T., Caspi, A. \& Taylor, A. (2003). Life with (or without) father: The benefits of living with the biological parents depend on the father's antisocial behavior. Child Development, 74 (1), 109-26.

Jordan, P. L. (1990). Laboring for relevance: Expectant and new fatherhood. Nursing Research, 39 (1), 11-16.

Martin, A, Ryan, R. \& Brooks-Gunn, J. (2007). The joint influence of mother and father parenting on child cognitive outcomes at age 5. Early Childhood Research Quarterly, 22, 423-39.

NICHD Early Child Care Research Network (2004). Fathers' and mothers' parenting behavior and beliefs as predictors of children's social adjustment in the transition to school. Joumal of Family Psychology, 18 (4), 628-38.

Nichols, M. (1993). Paternal perspectives of the childbirth experience. Maternal Child Nursing Joumal, 21 (3), 99-108.

Paquette, D. (2004). Theorizing the father-child relationship: Mechanisms and developmental outcomes. Human Development, 47 (4), 193-219.

Ramchandani, P., Stein, A., Evans, J. \& O'Connor, T. (2005). Paternal depression in the postnatal period and child development: A prospective population study. Lancet, 365, 2201-5.

Russell, G., Batclay, L., Edgecombe, G., Donovan, J., Habib, G., Callaghan, H. et al. (1999). Fitting Fathers into Families: Men and the Fatherhood Role in Contemporary Australia. Commonwealth Department of Family and Community Services, Canberra.

Scourfield, J. (2006). The challenge of engaging fathers in the child protection process. Critical Social Policy, $26(2), 440-9$.

Smith, N. (1999). Antenatal classes and the transition to fatherhood: A study of some fathers'views (Part 1). MIDIRS Midwifery Digest, 9 (3), 327-30.

van ljzendoorn, M. \& De Wolff, M. (1997). In search of the absent father - metaanalysis of infant-father attachment: A rejoinder to our discussants. Child Development, 68 (4), 604-9.

Videon, T. (2005). Parent-child relations and children's psychological well-being: Do dads matter? Joumal of Family Issues, 26, 55-78. 